\title{
Formation of poly(acrylic acid)/alumina composite via in situ polymerization of acrylic acid adsorbed within oxide pores
}

\author{
Bin Wang ${ }^{1, *}$, Ya-Ping Wang ${ }^{1}$, Peng Zhou ${ }^{1}$, Zhong-Qing Liu ${ }^{1}$, Shi-Zhong Luo ${ }^{1}$, Wei Chu ${ }^{1}$, \\ Zhanhu Guo ${ }^{2, *}$ \\ ${ }^{1}$ College of Chemical Engineering, Sichuan University, Chengdu, Sichuan, 610065, \\ PR China \\ ${ }^{2}$ Integrated Composites Laboratory (ICL), Chemical and Biomolecular Engineering \\ Department, University of Tennessee, Knoxville, Tennessee 37996, USA
}

\begin{abstract}
Poly(acrylic acid) (PAA) adsorption on alumina has been widely studied to provide composite materials. This work attempts to form PAA/alumina composites via in situ polymerization of acrylic acid pre-adsorbed on alumina. Effective acrylic acid adsorption in porous $\gamma$-alumina was realized with incipient wetness impregnation method. The adsorbed acrylic acid was then polymerized via reversible addition fragmentation transfer (RAFT) polymerization in aqueous medium. The solution properties of the as-prepared PAA/alumina composites were further investigated. Dissociation constant measurements illustrate that PAA molecules residing in alumina exhibited $\mathrm{pK}$ a more basic than pure PAA. The composites showed higher lead adsorption capability than pristine alumina. However, there correlation of lead adsorption capability and the adsorbed PAA amount in PAA/alumina samples did not follow a straightforward pattern.
\end{abstract}


Ion adsorption difference among various PAA segments was proposed.

Keywords: lead ion sorption; poly(acrylic acid); polyelectrolyte dissociation constants; polymer/alumina composite; RAFT polymerization

${ }^{*}$ Corresponding author: Tel. (+86) 28-85464466; fax (+86) 28-85403422; E-mail bin_wang@scu.edu.cn; zguo10@utk.edu 


\section{Introduction}

Predetermined mechanical, chemical, or physical properties can be adjusted by combining inorganic and organic components at the molecular level to form composites [1]. In composite materials, the inorganic skeleton provides the mechanical stability to the hybrid, while the functional groups of the organic molecules can selectively perform various chemistries, such as absorbing heavy metal ions. Polymers are the most employed organic component in synthesizing composites. These composites can be synthesized via: polymer adsorption into the support pores or deposition inside layered silicates; polymerization of monomers inside the cavities of the support; covalently linking organic functionality to the support; or direct synthesis of the composites using the sol-gel process. Interactions between the inorganic and polymeric components of the composite can range from weak forces such as hydrogen bonding to strong covalent bonds.

Composites formed of infiltrated polymers inside inorganic support pores are of special interests. The polymeric network fully penetrating the inorganic skeleton presents entanglement properties not encountered in systems where polymers only adsorbed on the external surface [2]. The composites are expected to display high mechanical and chemical stability, as well as other unique properties. For example, the externally adsorbed polymers exhibit the glass transition similar to free polymers, the polymer chains embedded inside mesoporous silica channels do not display glass transition effect. Meanwhile, encapsulation of polymer chains within support pores provides protection against external environments such as aqueous solutions. 
Start with pre-formed, industrially available inorganic support materials, composites with infiltrated polymers can be prepared either by polymer infiltration or in situ polymerization. The polymer infiltration process has been shown to take place in two stages, a rapid initial adsorption followed by a slow penetration into the pores. Pore size, polymer dimensions, ionic strength, and polymer concentration are the factors that affect the adsorption process. For example, Caruso et al. have studied the adsorption properties of polymer into metal oxide mesoporous pores [3,4]. Their studies conclude that polymer size and pore size are the most influential factors for the polymer infiltration in nano/mesoporous particles. Large pores are capable of adsorbing a broad range of molecular weight polymers.

Polymers have a certain degree of bulkiness that prevents them from infiltrating small openings/connections of the support pores. In order to fully fill the pore volume of the support materials, in situ polymerization of appropriate monomers offers a more promising means because monomer are much more feasible to penetrate narrow openings of the support. Atom transfer radical polymerization (ATRP) can be readily performed in aqueous or mixed aqueous media using monomers bearing various functional groups [5]. ATRP has been utilized to synthesize nanocomposite to provide a layer of well-defined polymer chains attached to inorganic particle surface [6,7].

Poly(acrylic acid) (PAA) is a well-known $\mathrm{pH}$-responsive polymer that has been used as pharmaceutical carriers, anti-fouling agents, flocculants, and superabsorbers [8]. Acrylates with a wide range of side chains have been polymerized using the controlled free radical polymerization process [5]. When using ATRP to synthesize PAA, the 
coordination between acrylic acid monomer and metal catalyst causes ill-controlled polymers [9]. Reversible addition fragmentation transfer (RAFT) polymerization of acrylic acid yields high molecular weight PAA with narrow polydispersity, as well as good miscibility with inorganic particles [10]. The RAFT polymerization of acrylic acid method can be readily employed in aqueous solution by using a trithiocarbonate chain transfer agent [11]. In the presence of inorganic support materials, acrylic acid has been incorporated into composite materials via in situ polymerization [5]. In the composites, the polymer layer demonstrates controlled thickness and functionality, affording the composite materials tailored physical properties such as wettability and etching resistance [5]. Exfoliation of layered double hydroxide [12] or montmorillonite [13-15] has been realized by intercalation of acrylic acid monomer followed by in situ living polymerization.

As for the inorganic support, we choose alumina that is one of the most studied metal oxides being widely utilized in water purification to remove dissolved inorganic and organic contaminants [16]. Among various forms, $\gamma-\mathrm{Al}_{2} \mathrm{O}_{3}$ is formed by heating boehmite $\mathrm{AlO}(\mathrm{OH})$ between 400 and $500{ }^{\circ} \mathrm{C}$. It has a specific surface area of $100-300 \mathrm{~m}^{2} / \mathrm{g}$. Upon heating, adjacent $-\mathrm{OH}$ groups can react to release water. The reported isoelectric point for alumina is $\mathrm{pH}$ 7.2-9 [17]. PAA/alumina interpenetrated composites have been synthesized via the in situ polymerization route in combination with sol-gel preparation of alumina $[18,19]$. Also, in situ radical polymerization of acrylic acid has been attempted in the presence of alumina powders dispersed in PAA aqueous solution [20]. Alumina particles are believed to be immobilized within the polymer matrix. 
One application area of the PAA/alumina composites is for heavy metal ion removal. Alumina is a major component in soils, aquifer materials, and sediments that has active surface sites for sorption of metal ions [21]. Abundantly existing in natural environment, alumina particles adsorb organic matter, primarily humic substances, to form a hybrid complex. The properties of minerals can be significantly changed upon adsorption of humic substances [22]. Regarding metal ion sorption, humic substances can either increase metal ion sorption by offering complexation sites, or decrease sorption by blocking active sites on mineral surface. To better understand such processes, one commonly employed method is to use a binary system composed of a surrogate polymer that highly resembles humic substances, and alumina particles. Synthetic poly(acrylic acid) (PAA) has been widely used as such a surrogate [23]. Investigation of the binary PAA/alumina system becomes a valuable tool to illustrate the behavior of the humic substance and mineral hybrid that is extensively present in soil.

Interactions between PAA and alumina govern the properties of the PAA/alumina hybrid like adsorption and dispersion. Characteristics of the particles, polymer, and the mixing solution all contribute to the process [24]. The size, morphology, and charge of the inorganic material, the conformation, molecular weight, and concentration of the organic matter, and the ionic strength and $\mathrm{pH}$ of the reaction media have been studied to understand the interactions between PAA and alumina. We have previously investigated small molecular weight PAA adsorption into porous alumina channels [25]. We found the polymer conformation was critical for the chain adsorption inside the alumina pores. Per metal ion sorption of the composite materials, adsorption of $\mathrm{Cd}^{2+}$ onto the PAA/alumina 
composite is influenced by the solution $\mathrm{pH}$ [21]. Below $\mathrm{pH} \mathrm{6}$, the composite is advantageous for metal ion sorption. Above $\mathrm{pH} \mathrm{6,} \mathrm{a} \mathrm{decreased} \mathrm{metal} \mathrm{ion} \mathrm{sorption} \mathrm{is}$ discovered due to the enhanced Cd-PAA complex dissolution. The interpenetrated PAA/alumina composites synthesized by combined in situ polymerization of acrylic acid and sol-gel preparation of alumina have been shown to adsorb metal ions following Langmuir isotherms [19]. The sorption of different cations has been tested to demonstrate a sorption order: $\mathrm{Ni}^{2+}<\mathrm{Cu}^{2+}<\mathrm{Cd}^{2+}<\mathrm{Pb}^{2+}$.

In this study, we explore the preparation of PAA/alumina composites via the RAFT route starting from acrylic acid and alumina particles, with all manipulations performed in aqueous or mixed aqueous media. An in situ radical polymerization of monomer molecules pre-adsorbed on alumina was used to form poly(acrylic acid) inside alumina pores. Radical polymerization has been realized by chain growth inside the channels of micro- and mesoporous molecular sieves [26]. According to the article, pores of molecular sieves were filled with methacrylate molecules via gas phase infiltration to prepare the composite. In our experiment, we apply solution infiltration of monomer molecules for better industrial adaptability. Adsorption of acrylic acid on alumina is dominated by carboxylate group bridging two $\mathrm{Al}$ atoms [27]. The adsorption of monoand dicarboxylic acids with 1-7 carbons on alumina surface is considered a self-assembled monolayer [28]. We expect it to be very viable to include acrylic acid inside $\gamma$-alumina pores in aqueous solution.

\section{Experimental}




\subsection{Materials}

Acrylic acid and carbon disulfide were acquired from Chengdu Kelong Chemical Co. (China). Ethanethiol, 2-bromobutyric acid, and 4,4'-azobis(4-cyanovaleric acid) (V501) were purchased from Chengdu Best Chemicals Co. Ltd. (China). $\gamma$-Alumina was obtained from Kemiou Chemical Co. (Tianjin, China), and its grinded powders in 40-60 mesh range were activated at $500{ }^{\circ} \mathrm{C}$ for $3 \mathrm{~h}$ prior to use. Other reagents were of analytical grade. Deionized water was used with a conductivity of $\leq 1.0 \mu \mathrm{S} \mathrm{cm}-1$. All reagents were used as received without further purification unless stated otherwise.

\subsection{Synthesis of RAFT chain transfer agent (CTA)}

The RAFT chain transfer agent (CTA) was prepared following the literature route $[11,29,30]$. Briefly, a $50-\mathrm{mL}$ three-neck flask charged with $\mathrm{NaOH}(1.2 \mathrm{~g}$, in 50 wt.\% solution), EtSH (2.25 mL, $30.0 \mathrm{mmol}), \mathrm{CS}_{2}(1.68 \mathrm{~mL}, 28.0 \mathrm{mmol})$, acetone $(1.5 \mathrm{~mL})$, and water $(5.0 \mathrm{~mL})$ was reacted for $10 \mathrm{~min}$ and then placed in ice bath. 2-Bromobutyric acid $(3.2 \mathrm{~mL}, 30.0 \mathrm{mmol})$ and $50 \% \mathrm{NaOH}(2.4 \mathrm{~mL})$ were added drop-wise in sequence. After addition, the ice bath was removed and water $(5.0 \mathrm{~mL})$ was added. The solution was stirred for $20 \mathrm{~h}$, followed by quenching in ice water. The mixture was added with $50 \%$ $\mathrm{HCl}(10 \mathrm{~mL})$, extracted with hexane $(20 \mathrm{~mL})$. The organic phase was further washed with water $(20 \mathrm{~mL})$ for five times until becoming colorless. The oil-like liquid was dried over $\mathrm{MgSO}_{4}$, filtered, and then evaporated to remove hexane at $50^{\circ} \mathrm{C}$. The RAFT CTA was obtained as a dark-orange oil. Yield: $2.61 \mathrm{~g}$ (11.63 mmol), 41.5\% based on CS2.

${ }^{1} \mathrm{H} \quad \mathrm{NMR} \quad\left(\mathrm{CDCl}_{3}\right): 4.81 \quad\left(1 \mathrm{H},-{ }_{\mathrm{C} H}-\mathrm{CH}_{2}-\mathrm{CH}_{3}\right), \quad 3.37 \quad\left(2 \mathrm{H},-\mathrm{CH}_{2}-\mathrm{CH}_{3}\right), \quad 2.00 \quad(2 \mathrm{H}$, $\left.-\mathrm{CH}-\mathrm{CH}_{2}-\mathrm{CH}_{3}\right), 1.36\left(3 \mathrm{H},-\mathrm{CH}_{2}-\mathrm{CH}_{3}\right), 1.08\left(3 \mathrm{H},-\mathrm{CH}-\mathrm{CH}_{2}-\mathrm{CH}_{3}\right)[11,29,30]$. 


\subsection{RAFT preparation of PAA/alumina composites}

The preparation of PAA/alumina composites were conducted in two steps. The first step was the adsorption of acrylic acid (AA) in ethanol solution into alumina pores [10]. This was achieved in two fashions, wet impregnation and incipient wetness impregnation. During the RAFT process, acrylic acid monomers are usually distilled to remove added inhibitors. Our preliminary results demonstrated that in the presence of alumina particles, the impurities in monomers would not alter polymerization significantly so distillation operation was omitted. In the following operations, acrylic acid was used without prior distillation. AA was dissolved in ethanol to afford 10, 50, or $90 \mathrm{v} . \%$ solutions. In wet impregnation, $5.0 \mathrm{~g}$ of activated alumina was added to AA ethanol solution $(50 \mathrm{~mL})$, gently stirred for $12 \mathrm{~h}$, filtered, and rinsed with water five times to removed externally adsorbed AA. In incipient wetness impregnation, alumina (5.0 g) was added with AA ethanol solution $(2.0 \mathrm{~mL})$ and standing for $1 \mathrm{~h}$. The acrylic acid soaked alumina samples were labeled $\mathrm{M}_{n, x} / \mathrm{Al}$, where $n=10$, 50 , or $90 \%$, and $x$ stands for wet or incipient wetness impregnation.

After adsorption with acrylic acid, alumina (4.5 g) was added with CTA and V501 (both in $50 \% \mathrm{NaOH}$ solution). The amounts of the two reagents were calculated according to adsorbed acrylic acid (determined via thermogravimetry): AA:CTA:V501 = 40:1:0.1 in molar ratios. The mixture was added with water $(20 \mathrm{~mL})$, stirred at $65^{\circ} \mathrm{C}$ for 8 h, quenched with ice water. The mixture was then adjusted to $\mathrm{pH} 5.0-5.5$ using $\mathrm{NaOH}$, filtered and rinsed repeatedly, and dried at $60{ }^{\circ} \mathrm{C}$ for $10 \mathrm{~h}$. The prepared samples were labeled $\mathrm{P}_{n, x} / \mathrm{Al}$, where $n$ and $x$ take the same meanings as in $\mathrm{M}_{n, x} / \mathrm{Al}$. 


\subsection{Solution properties of PAA/alumina composites}

A batch equilibrium procedure was employed to analyze the solution properties of the formed composite materials. A certain amount of composite sample, based on measured PAA content, was dispersed with $\sim 5 \mathrm{~mL}$ water. An aliquot of $0.20 \mathrm{~mL}$ of 0.025 $\mathrm{M} \mathrm{NaOH}$ was titrated into the dispersion under swirling. After equilibration time, the $\mathrm{pH}$ value of the dispersion was taken.

A batch equilibrium procedure was employed to analyze the metal ion sorption properties of the composites while all results were reported as the average of a triplicate. Lead content of the supernatant was directly analyzed with atomic absorption spectrophotometry (AAS). When the lead content of a solid was to be determined, the solid was dissolved with 50\% phosphoric acid, diluted with water, and analyzed with AAS. The lead sorption kinetics was analyzed by filtering the sorption solution at different time intervals and measuring the $\mathrm{Pb}$ content of the supernatant. The effect of $\mathrm{Pb}^{2+}$ concentration on sorption amount was tested in $\mathrm{Pb}\left(\mathrm{NO}_{3}\right)_{2}$ solutions. When preparing $\mathrm{Pb}\left(\mathrm{NO}_{3}\right)_{2}$ solution of high $\mathrm{Pb}^{2+}$ concentrations, the solution $\mathrm{pH}$ needed to be adjusted using $\mathrm{NaOH}$. When the solution $\mathrm{pH}$ was above 5.5, the solution started to form precipitation. $\mathrm{So} \mathrm{Pb}\left(\mathrm{NO}_{3}\right)_{2}$ solutions of $\mathrm{pH}$ 5.0-5.1 were used.

\subsection{Characterization}

Room temperature Fourier transform infrared (FT-IR) spectroscopy (Perkin Elmer Spectrum Two) was acquired from $\mathrm{KBr}$ pellets, of which $1 \mathrm{wt} . \%$ was the sample, in the range of $4000-400 \mathrm{~cm}^{-1}$. Proton nuclear magnetic resonance ( ${ }^{1} \mathrm{H}$ NMR) (Bruker Avance II-400MHz) was performed using $\mathrm{CDCl}_{3}$ as the solvent. Mass spectrometry (Thermo 
Finnigan TSA Quantum Ultra) was recorded in the range of $m / z=100-300$. Thermogravimetry (TG) (HCT-2 Differential Thermal Balance, Beijing Hengjiu Scientific Instrument Co.) was operated in the range of $80-700{ }^{\circ} \mathrm{C}$ in air. The sample was initially heated to $80^{\circ} \mathrm{C}$ for $20 \mathrm{~min}$ to remove atmospheric water. The process was monitored until the weight variation reached a level of $\leq 0.01 \mathrm{mg}$. The sample was then heated to $130{ }^{\circ} \mathrm{C}$ at a heating rate of $10{ }^{\circ} \mathrm{C} \mathrm{min}-1$. After this point, the heating rate was changed to $2{ }^{\circ} \mathrm{C} \mathrm{min}-1$ until $150{ }^{\circ} \mathrm{C}$, and the sample was held for an additional $10 \mathrm{~min}$ at this temperature for the complete removal of AA (boiling point of $141{ }^{\circ} \mathrm{C}$ ). Per experimental recording, decarboxylation occurred around $400{ }^{\circ} \mathrm{C}$. From $150^{\circ} \mathrm{C}$, the heating rate was set to be $10^{\circ} \mathrm{C}$ $\min ^{-1}$ until $350{ }^{\circ} \mathrm{C}$. After this temperature, the heating rate was changed to $5^{\circ} \mathrm{C} \min ^{-1}$ until $500{ }^{\circ} \mathrm{C}$ for the complete decomposition of organic matters. The specific surface areas, total pore volumes, and average pore diameters were determined from the nitrogen adsorption-desorption isotherms at $-196{ }^{\circ} \mathrm{C}$, which were measured using an automated surface area and pore size analyzer (Quantachrome NOVA 1000e). Before each measurement, the samples were degassed in vacuum at $300{ }^{\circ} \mathrm{C}$ for $3 \mathrm{~h}$. Specific surface areas of samples were calculated by the Brunauer-Emmett-Teller (BET) method, and the pore size distribution and average pore diameter were determined according to the Barrett-Joyner-Halenda (BJH) method applied to desorption isotherms. Lead content was measured with atomic absorption spectrophotometry (AAS) (AA32DCRT, Shanghai Analytical Instrument Co., China). Aqueous lead standard solutions were prepared from $\mathrm{Pb}\left(\mathrm{NO}_{3}\right)_{2}$ to obtain standards for AAS.

\subsection{Geometric parameters of infiltrated PAA}


We combine the TG and BET/BJH results to estimate the geometric parameters of infiltrated PAA, and use values directly reported in Tables 1 and 2. The pristine alumina has an average surface area of $S_{\mathrm{A}} \times 10^{4} \mathrm{~cm}^{2}$, pore diameter of $d_{\mathrm{A}}=2 r_{\mathrm{A}} \mathrm{nm}$ and pore volume of $V_{\mathrm{A} \mathrm{cm}} \mathrm{g}^{-1}$. Assume the predominant pore volume takes a tube form, then the total length of tubes in one gram of alumina is $l=\frac{V_{\mathrm{A}}}{\pi r_{\mathrm{A}}^{2}} \times 10^{14} \mathrm{~cm}$. In one gram of composite sample, the mass of PAA measured with TG is $M$ mg. Take an approximate PAA density of $1.23 \mathrm{~g} \mathrm{~cm}^{-3}$ according to the supplier, this gives a volume of $0.813 \mathrm{M} \times 10^{-3}$ $\mathrm{cm}^{3}$. Assume PAA covers alumina surface as a uniform, evenly distributed layer, the thickness of the layer becomes $h=\frac{0.813 M}{\left(\frac{1000-M}{1000}\right) S_{\mathrm{A}}} \mathrm{nm}$. Subtracting this value from the pristine alumina pore diameter, the composite sample should have a pore diameter of $2 r_{\mathrm{C}}=d_{\mathrm{C}}=$ $\left(d_{\mathrm{A}}-2 h\right) \mathrm{nm}$. The corresponding volume is $V_{\mathrm{C}}=\pi r_{\mathrm{C}}^{2} l \times 10^{-14}=\frac{r_{\mathrm{C}}^{2}}{r_{\mathrm{A}}^{2}} V_{\mathrm{A}} \mathrm{cm}^{3}$, and surface area is $S_{\mathrm{C}}=\pi d_{\mathrm{C}} l \times 10^{3} \mathrm{~m}^{2}$ for the composite. The calculated such values of $\mathrm{P}_{10, \mathrm{in}} / \mathrm{Al}$ and $\mathrm{P}_{90, \mathrm{in}} / \mathrm{Al}$ are shown in Table 3, along with measured values.

\section{Results and discussion}

\subsection{Synthesis of RAFT chain transfer agent (CTA)}

The asymmetric trithiocarbonate RAFT chain transfer agent (CTA) was synthesized according to Scheme 1 following literature procedures. The FT-IR of the product shows $\mathrm{S}-\mathrm{H}$ stretching at $2583 \mathrm{~cm}^{-1}[29,31], \mathrm{C}=\mathrm{S}$ stretching at 1265 and $1045 \mathrm{~cm}^{-1}[29,32-35]$, and C-S stretching at $653 \mathrm{~cm}^{-1}$ [35] (Figure 1). The ${ }^{1} \mathrm{H}$ NMR spectrum is shown in Figure 2. The peaks at 3.37 and $1.36 \mathrm{ppm}$ are the combined contributions of the product CTA and the starting material EtSH [11,29,30]. To sufficiently remove the impurity EtSH, repeated purification 
operations would be required that would have resulted in severely diminished product yield. Meanwhile, the presence of the impurity did not interfere with the RAFT reaction. Therefore, further purification of the product CTA was not performed. Mass spectrum of the product shows the molecular ion peak of $m / z=224.66$ (Figure 3). The peak separated by $15 \mathrm{~m} / \mathrm{z}$ is assigned to the loss of $-\mathrm{CH}_{3}, 27 \mathrm{~m} / z$ to $-\mathrm{CH}_{2} \mathrm{CH}_{3}$, and $54 \mathrm{~m} / z$ to two $-\mathrm{CH}_{2} \mathrm{CH}_{3}$.

\subsection{Adsorption of acrylic acid (AA) in alumina}

The adsorption of acrylic acid in alumina in aqueous solution was reported in the fashion of a monolayer acrylic acid coverage [36]. The FT-IR spectra of AA-adsorbed alumina samples are presented in Figure 4a. Compared to pristine alumina, acrylic acid adsorption was unveiled by the peak at $1722 \mathrm{~cm}^{-1}$, assigned to the symmetric stretch of $-\mathrm{CO}_{2} \mathrm{H}$ [22]. The peaks at $1580-1550$ and $\sim 1460 \mathrm{~cm}^{-1}$ are assigned to the asymmetric and symmetric stretches of $-\mathrm{CO}_{2}{ }^{-}$, respectively, indicative of the dimeric binding mode [27]. Because of the strong $-\mathrm{OH}$ bending vibration of alumina at $1640 \mathrm{~cm}^{-1}[25,37]$, the $\mathrm{C}=\mathrm{C}$ vibration of adsorbed acrylic acid at $1634 \mathrm{~cm}^{-1}$ was not observed in the spectra [12].

The TG traits of AA-adsorbed alumina samples are displayed in Figures 5a and 5c. Inflection points at 150 and $450{ }^{\circ} \mathrm{C}$ are due to heating program changes. We notice that there was minimal weight loss until $150^{\circ} \mathrm{C}$, arising from the loss of water and acrylic acid (boiling point $141^{\circ} \mathrm{C}$ ). The following degradation stages of the $\mathrm{M} / \mathrm{Al}$ samples resemble that of $\mathrm{P} / \mathrm{Al}$ samples, and will be discussed in the following section. Higher acrylic acid concentrations yielded more organic matter adsorbed in alumina for both wet and incipient wetness impregnation methods (Table 1). Adsorption efficiency indicates the ratio of organic matter measured via TG against the added acrylic acid amount in each 
sample. For incipient wetness impregnation, the adsorbed acrylic acid was more efficiently retained at lower adsorbed amount after post-adsorption operations such as wash and drying. With $10 \%$ acrylic acid solution, wet impregnation afforded the least organic adsorption among all samples, $93 \mu \mathrm{g} \mathrm{m}^{-2}$. Higher solution acrylic acid concentrations (50\% and 90\%) provided samples with $\sim 280 \mu \mathrm{g} \mathrm{m} \mathrm{m}^{-2}$ acrylic acid adsorption.

The oxide surface area occupied by adsorbed organic matter can be expressed in terms of monolayers. The occupied area of a molecule in the monolayer coverage pattern can be calculated according to the following equation [38]:

$$
A=6.354\left(\frac{T_{\mathrm{c}}}{p_{\mathrm{c}}}\right)^{\frac{2}{3}}\left(\AA^{2}\right)
$$

where $T_{\mathrm{c}}$ is the critical temperature, and $p_{\mathrm{c}}$ is the critical pressure. Using the values of $T_{\mathrm{c}}$ and $p_{\mathrm{c}}$ for acrylic acid [39], the calculated area for one acrylic acid molecule is $3.10 \times 10^{-19}$ $\mathrm{m}^{2}$. Combine the area coverage and TG data, the values of acrylic acid monolayer coverage of alumina surface are listed in Table 1 . The estimated acrylic acid coverage by using a single acrylic acid molecule area is close to that determined by TG discussed in the previous paragraph. The highest adsorbed acrylic acid from aqueous solution was determined to be $342 \mu \mathrm{g} \mathrm{m} \mathrm{m}^{-2}$ when the acrylic acid molecules were stacked in a monolayer fashion [36]. The adsorbed acrylic acid with the wet impregnation method in ethanol solution (50\% and $90 \%$ ) was close to the monolayer coverage. Using incipient wetness impregnation, higher acrylic acid adsorption than monolayer was achieved with solution concentrations of $50 \%$ and $90 \%$. Incipient wetness impregnation appears a superior method for incorporating more acrylic acid in alumina. In the case of $\mathrm{M}_{90, \mathrm{in}} / \mathrm{Al}$, 
the adsorbed acrylic acid could occupy the alumina surface in a three-monolayer fashion.

\subsection{RAFT preparation of PAA/alumina composites}

In situ polymerization of acrylic acid in the presence of alumina particles was performed in aqueous solution. The FT-IR spectra of the composite samples are very similar to that of $\mathrm{M} / \mathrm{Al}$, showing peaks at $1580-1550$ and $\sim 1460 \mathrm{~cm}^{-1}$ of $-\mathrm{CO}_{2}^{-}$(Figure $4 \mathrm{~b}$ ). Because the samples were neutralized after polymerization, the peak at $1722 \mathrm{~cm}^{-1}$ of $-\mathrm{CO}_{2} \mathrm{H}$ was absent.

The TG curves of the composite samples are displayed in Figures 5b, 5d. For pure PAA, a typical TG curve has three stages [15]. Below $150{ }^{\circ} \mathrm{C}$, the release of water is accounted for the loss of mass. Between 150 to $350^{\circ} \mathrm{C}$, dehydration and decarboxylation of PAA contribute to the loss of mass. From 350 till $500{ }^{\circ} \mathrm{C}$, the total chain breakdown and full combustion of the polymer occur. The $\mathrm{P} / \mathrm{Al}$ samples demonstrate similar trends to that of pure PAA, especially those with relatively higher PAA contents $\left(\mathrm{P}_{50, \text { in }} / \mathrm{Al}\right.$ and $\mathrm{P}_{90, \mathrm{in}} / \mathrm{Al}$ ). An interesting point is that some acrylic acid monomer adsorbed samples (i.e., $\mathrm{M}_{50, \mathrm{in}} / \mathrm{Al}$ and $\mathrm{M}_{90, \mathrm{in}} / \mathrm{Al}$ ) present similar curves (Figure 5c). The phenomenon implies that polymerization of adsorbed acrylic acid monomers might have occurred during the heating process of TG measurement. There is loss of adsorbed acrylic acid during the polymerization process because all $\mathrm{P} / \mathrm{Al}$ samples show retention efficiencies less than unity, some far from that (Table 2). Adsorbed acrylic acid molecules might be re-dissolved and re-distributed in the aqueous polymerization solution. During the RAFT polymerization, the acrylic acid molecules both inside and outside the alumina pores undergo polymerization to form PAA molecules, but those outside the pores will 
be distributed on the outer walls of the oxide (Scheme 2). Retention efficiency is the ratio of the organic matter measured via TG against the adsorbed amount of acrylic acid monomer before polymerization. Again, incipient wetness impregnation affords higher PAA amounts in the composite than wet impregnation does. In a similar approach to that of monomer coverage, the alumina surface covered by PAA in terms of monolayer is given in Table 2.

The physical characterization in terms of specific surface area, pore diameter, and pore volume was performed on $\mathrm{P}_{10, \text { in }} / \mathrm{Al}$ and $\mathrm{P}_{90, \text { in }} / \mathrm{Al}$ (Table 3). The selection of these two composite samples was based on their adsorbed organic matter, i.e., the former having very small amount while the latter having the most among all composite samples. As expected, the pristine alumina presented the greatest BET specific surface area. After monomer adsorption and in situ polymerization, the composites samples experienced decreased specific surface areas because of polymer infiltration. If the adsorbed PAA would have taken a uniform coverage of the alumina surface, the theoretical specific surface area, pore volume, and pore diameter of samples $\mathrm{P}_{50, \mathrm{in}} / \mathrm{Al}$ and $\mathrm{P}_{90, \mathrm{in}} / \mathrm{Al}$ can be calculated based on the PAA content measured by TG (Table 3). Compare the calculated and measured values, the polymer distribution in these two samples seems contradictory. For $\mathrm{P}_{90, \mathrm{in}} / \mathrm{Al}$ with the highest adsorbed PAA amount, both calculated specific surface area and pore volume are smaller than the measured, and the pore diameter is greater. The explanation is that a significant portion of PAA existed on the outside surface of alumina particles and the pore infiltration by polymer chains was insufficient. On the other hand, for $\mathrm{P}_{10, \mathrm{in}} / \mathrm{Al}$, the theoretical specific surface area and pore volume values are larger than 
that of measured. The explanation of this discrepancy is that the pore channels of alumina were not uniform. Some narrower parts of the channels were clogged by the formed polymer, resulting some dead surface area and pore volume not accessible to $\mathrm{N}_{2}$ molecules during the measurement.

\subsection{Solution properties of PAA/alumina composites}

Solution properties of composites $\mathrm{P}_{10, \mathrm{in}} / \mathrm{Al}$ and $\mathrm{P}_{90, \mathrm{in}} / \mathrm{Al}$ were analyzed by the $\mathrm{pH}$ titration method. The dissociation constant of PAA was determined by the $\mathrm{pH}$ titration method [40]:

$$
K_{\mathrm{a}}=\left[\mathrm{H}^{+}\right]\left\{\frac{\left[\mathrm{L}^{-}\right]}{[\mathrm{HL}]}\right\}^{\beta}
$$

where $\beta$ is a constant between 1 and 2. Rearrangement gives the relation between the $\mathrm{pH}$ and the degree of neutralization $\alpha$ in the modified Henderson-Hasselbach equation [40,41]:

$$
\mathrm{pH}=\mathrm{p} K_{\mathrm{a}}-\beta \log \left(\frac{1-\alpha}{\alpha}\right)
$$

The equation states that for a given polymer type, the values of $K_{\mathrm{a}}$ and $\beta$ are independent of polymerization degree. For a simple weak acid such as acetic acid, $\beta$ is unity.

The $\mathrm{pH}$ value versus $\log [(1-\alpha) / \alpha]$ is plotted in Figure 6. It is found that for $\mathrm{P}_{10, \mathrm{in}} / \mathrm{Al}$, the plot is linear in the $\mathrm{pH}$ range of $4.95-7.38$ while the $\mathrm{pH}$ range for $\mathrm{P}_{90, \mathrm{in}} / \mathrm{Al}$ is $4.90-6.74$ with $R^{2} \geq 0.999$ for both. Using the slope and intercept values, the $\mathrm{p} K_{\mathrm{a}}$ and $\beta$ values of the two composites were calculated (Table 4). The $\mathrm{pK}$ a values of the two composites are higher than pristine PAA $\left(\mathrm{p} K_{\mathrm{a}}=4.75\right) .{ }^{42}$ Between the two composite samples, the more ratio of alumina $\left(\mathrm{P}_{10, \mathrm{in}} / \mathrm{Al}\right)$, the higher $\mathrm{p} K_{\mathrm{a}}$ of the composite material. Sample $\mathrm{P}_{10, \mathrm{in}} / \mathrm{Al}$ has a higher $\beta$ value than $\mathrm{P}_{90, \mathrm{in}} / \mathrm{Al}$, indicating less carboxylic acid amount per material mass. 


\subsection{Lead sorption on PAA/alumina}

Metal ion sorption on PAA/alumina composites depends on the solution $\mathrm{pH}$ range [21]. In the PAA/alumina composites, carboxylic acid groups are considered the predominant metal ion sorption sites. Metal ions on the composites may proceed through ion exchange with $-\mathrm{COOH}$, or complexation with $-\mathrm{COO}^{-}$[19]. On the other hand, the stability constant of $\mathrm{Pb}(\mathrm{II})-\mathrm{PAA}(6.75-7.0)$ is higher than $\mathrm{Pb}(\mathrm{II})$-alumina (6.0), but there exist enough strong-adsorbing sites on alumina for metal ion to bind [23].

Lead sorption on $\mathrm{P}_{n, x} / \mathrm{Al}$ samples were performed in a batch equilibrium procedure. In a typical experiment, an aliquot of $\mathrm{Pb}^{2+}$ solution $(25 \mathrm{~mL})$ was added with $\mathrm{P}_{n, x} / \mathrm{Al}(0.0100$ $\pm 0.0002 \mathrm{~g}$ ), standing for various time periods, and filtered. Examination of the adsorption curves of pristine alumina, $\mathrm{P}_{10, \mathrm{in}} / \mathrm{Al}$, and $\mathrm{P}_{90, \mathrm{in}} / \mathrm{Al}$ reveals that the three samples behaved highly similarly toward lead sorption (Figure 7a). After about $30 \mathrm{~min}$, all samples had reached the adsorption plateau. The adsorption processes of the three samples with very different PAA amounts incorporated (0, 1/4-monolayer, 2-monolayer) highly resemble each other, suggesting that PAA directly attached to alumina surface contributed significantly to lead ion sorption (vide infra). The effect of metal ion concentration on lead sorption in pristine alumina, $\mathrm{P}_{10, \mathrm{in}} / \mathrm{Al}$ and $\mathrm{P}_{90, \mathrm{in}} / \mathrm{Al}$ was tested (Figure $7 \mathrm{~b}$ ). Adsorbed lead amount increased with higher $\mathrm{Pb}^{2+}$ solution concentration. Higher than $60 \mathrm{mg} \mathrm{L}^{-1}$, the adsorbed lead amount increment became stagnated. The validity of lead sorption experiments was further tested by analyzing the combined lead amounts both in the supernatant and the solid after adsorption (Table 5). The data demonstrate that the lead amounts from the combined supernatant and solid matched the initial lead amounts very 
well.

The adsorbed $\mathrm{Pb}(\mathrm{II})$ amount on each sample is shown in Figure 8 using a lead solution concentration of $60 \mathrm{mg} \mathrm{L}^{-1}$. Pristine alumina had shown considerable $\mathrm{Pb}(\mathrm{II})$ sorption capacity, while composite samples with PAA incorporated showed higher $\mathrm{Pb}(\mathrm{II})$ sorption capacities. However, the $\mathrm{Pb}(\mathrm{II})$ sorption on the composite samples does not correlate with the adsorbed PAA amount on alumina. According to the previous analysis, $\mathrm{P}_{90, \mathrm{in}} / \mathrm{Al}$ would contain a significant amount of PAA on the outside surface of alumina particles. The carboxylic acid groups in the extra PAA chains did not show great contribution to $\mathrm{Pb}(\mathrm{II})$ sorption. Within experimental error, we find that all $\mathrm{P}_{n, x} / \mathrm{Al}$ samples adsorbed similar amount of $\mathrm{Pb}(\mathrm{II})$. This implies that the PAA layer directly contacting alumina surface would be responsible for the metal ion sorption.

\section{Conclusion}

In situ polymerization of acrylic acid within $\gamma$-alumina pores was attempted to form PAA/alumina composites. The monomer molecules were adsorbed into the oxide pores via impregnation first, followed by RAFT polymerization in aqueous solution. The adsorbed monomer molecules might have re-dissolved in the solution during the polymerization process, leading to unevenly distributed polymer in the formed PAA/alumina composite samples. With high acrylic acid impregnation amount, a good portion of the formed PAA in the composite resided outside the alumina pores. With low acrylic acid impregnation amount, more of the formed PAA were located inside the oxide pores, but clogged some narrower channels. Thus there existed a discrepancy between 
PAA amount measured via thermogravimetry and the physical data determined via gas absorption/desorption. The solution properties of the composites were further analyzed. The $\mathrm{pK}$ a values of PAA in the composites became dependent on the alumina content. With higher alumina content in a composite sample, the $\mathrm{pK}$ a value of PAA moved to the higher $\mathrm{pH}$ range. The metal ion sorption properties of the composites seemed to be independent of PAA content in each sample. It is suggested the PAA layer adjacent to alumina was responsible for metal ion sorption. Among the PAA/alumina composites prepared, the one with the highest acrylic acid loading via the incipient wetness impregnation contained the most PAA after in situ polymerization, and its lead sorption was the highest.

\section{Acknowledgements}

This work was supported by the National Science Foundation of China (No. 21376154). 
1 C. Sanchez, B. Julián, P. Belleville, M. Popall, Applications of hybrid organic-inorganic nanocomposites, J. Mater. Chem. 15 (2005) 3559-3592.

2 S. Spange, A. Gräser, A. Huwe, F. Kremer, C. Tintemann, P. Behrens, Cationic host guest polymerization of $N$-vinylcarbazole and vinyl ethers in MCM-41, MCM-48, and nanoporous glasses, Chem. Mater. 13 (2001) 3698-3708.

3 Y. Wang, A.S. Angelatos, D.E. Dunstan, F. Caruso, Infiltration of macromolecules into nanoporous silica particles, Macromolecules 40 (2007) 7594-7600.

4 G.L. Drisko, P. Imperia, M. de los Reyes, V. Luca, R.A. Caruso, Size matters: Incorporation of poly(acrylic acid) and small molecules into hierarchically porous metal oxides prepared with and without templates, Langmuir 26 (2010) 14203-14209.

5 K. Matyjaszewski, J. Xia, Atom Transfer Radical Polymerization, Chem. Rev. 101 (2001) 2921-2990.

6 T. von Werne, T.E. Patten, Atom transfer radical polymerization from nanoparticles: A tool for the preparation of well-defined hybrid nanostructures and for understanding the chemistry of controlled/“living” radical polymerizations from surfaces, J. Am. Chem. Soc. 123 (2001) 7497-7505.

7 C. Perruchot, M.A. Khan, A. Kamitsi, S.P. Armes, T. von Werne, T.E. Patten, Synthesis of well-defined, polymer-grafted silica particles by aqueous ATRP, Langmuir 17 (2001) 4479-4481.

8 D. Reith, B. Müller, F. Müller-Plathe, S. Wiegand, How does the chain extension of poly (acrylic acid) scale in aqueous solution? A combined study with light scattering and computer simulation, J. Chem. Phys. 116 (2002) 9100-9106.

9 C. Ladavière, N. Dörr, J.P. Claverie, Controlled radical polymerization of acrylic acid in protic media, Macromolecules 34 (2001) 5370-5372.

10 J. Loiseau, Doërr, J.M. Suau, J.B. Egraz, M.F. Llauro, C. Ladavière, J. Claverie, Synthesis and characterization of poly(acrylic acid) produced by RAFT polymerization. Application as a very efficient dispersant of $\mathrm{CaCO}_{3}$, kaolin, and $\mathrm{TiO}_{2}$, Macromolecules 36 (2003) 3066-3077.

11 J. Ji, L. Jia, L. Yan, P.R. Bangal, Efficient synthesis of poly(acrylic acid) in aqueous solution via a RAFT process, J. Macromolecular Sci. A 47 (2010) 445-451.

12 S. Rey, J. Mérida-Robles, K.-S. Han, L. Guerlou-Demourgues, C. Delmas, E. Duguet, Acrylate intercalation and in situ polymerization in iron substituted nickel hydroxides, Polym. Int. 48 (1999) 277-282.

13 P.-S. Liu, L. Li, N.-L. Zhou, J. Zhang, S.-H. Wei, J. Shen, Synthesis and properties of a poly(acrylic acid)/montmorillonite superabsorbent nanocomposite, J. Appl. Polym. Sci. 102 (2006) 5725-5730.

14 Y. Zheng, J. Zhang, A. Wang, Fast removal of ammonium nitrogen from aqueous solution using chitosan-g-poly(acrylic acid)/attapulgite composite, Chem. Eng. J. 155 (2009) 215-222.

15 L. Solhi, M. Atai, A. Nodehi, M. Imani, A. Ghaemi, K. Khosravi, Poly(acrylic acid) grafted montmorillonite as novel fillers for dental adhesives: Synthesis, characterization and properties of the adhesive, Dental Mater. 28 (2012) 369-377.

16 M. Wiśniewska, S. Chibowski, T. Urban, Effect of the presence of cationic polyacrylamide on the surface properties of aqueous alumina suspension-stability mechanism, Appl. Surface Sci. 320 (2014) 843-851.

17 B. Kasprzyk-Hordern, Chemistry of alumina, reactions in aqueous solution and its 
application in water treatment, Adv. Colloid Interface Sci. 110 (2004) 19-48.

18 C.H. Campos, B.F. Urbano, B.L. Rivas, Synthesis and characterization of

organic-inorganic hybrid composites from poly(acrylic acid)-[3-(trimethoxysilyl)propyl

methacrylate]- $\mathrm{Al}_{2} \mathrm{O}_{3}$, Composites B 57 (2014) 1-7.

19 C.H. Campos, C.C. Torres, B.F. Urbano, B.L. Rivas, Effect of the coupling agent on the properties of poly(acrylic acid) $-\mathrm{Al}_{2} \mathrm{O}_{3}$ interpenetrating hybrids and sorption of metal ions, Polym. Int. 64 (2015) 595-604.

20 A. Lungu, A. Sârbu, V. Fruth, F. Constantin, M. Teodorescu, N. Petrov, New inorganic/organic composite obtained by gelcasting process as precursors for porous ceramic materials, Roman. J. Mater. 42 (2012) 172-178.

21 R.M. Floroiu, A.P. Davis, A. Torrents, Cadmium adsorption on aluminum oxide in the presence of polyacrylic acid, Environ. Sci. Technol. 35 (2001) 348-353.

22 K. Vermöhlen, H. Lewandowski, H.-D. Narres, E. Koglin, Adsorption of polyacrylic acid on aluminium oxide: DRIFT spectroscopy and ab initio calculations, Colloids Surfaces A 170 (2000) 181-189.

23 Y. Wang, F. Marc Michel, C. Levard, Y. Choi, P.J. Eng, G.E. Brown Jr. Competitive sorption of $\mathrm{Pb}$ (II) and $\mathrm{Zn}(\mathrm{II})$ on polyacrylic acid-coated hydrated aluminum-oxide surfaces, Environ. Sci. Technol. 47 (2013) 12131-12139.

24 K.K. Das, P. Somasundaran, Ultra-low dosage flocculation of alumina using polyacrylic acid, Colloids Surfaces A 182 (2001) 25-33.

25 L. Liu, S.-Z. Luo, B. Wang, Z. Guo, Investigation of small molecular weight poly (acrylic acid) adsorption on $\gamma$-alumina, Appl. Surface Sci. 345 (2015) 116-121.

26 K. Moller, T. Bein, R.X. Fischer, Entrapment of PMMA polymer strands in micro- and mesoporous materials, Chem. Mater. 10 (1998) 1841-1852.

27 A.R. Barron, The interaction of carboxylic acids with aluminum oxides: journeying from a basic understanding of alumina nanoparticles to water treatment for industrial and humanitarian applications, Dalton Trans. 43 (2014) 8127-8143.

28 S. Bertazzo, K. Rezwan, Control of $\alpha$-alumina surface charge with carboxylic acids, Langmuir 26 (2010) 3364-3371.

29 J. Ji, L. Yan, D. Xie, Surfactant-free synthesis of amphiphilic diblock copolymer in aqueous phase by a self-stability process, J. Polym. Sci. A 46 (2008) 3098-3107.

30 C.J. Ferguson, R.J. Hughes, D. Nguyen, B.T.T.T. Pham, R.G. Gilbert, A.K. Serelis, C.H. Such, B.S. Hawkett, Ab initio emulsion polymerization by RAFT-controlled self-assembly, Macromolecules 38 (2005) 84-93.

31 J.A. Carioscia, H. Lu, J.W. Stanbury, C.N. Bowman, Thiolene oligomers as dental restorative materials, Dental Mater. 21 (2005) 1137-1143.

32 B.N. Sağlık, Y. Özkay, Ü.D. Özkay, H.K. Gençer, Synthesis and biological evaluation of some novel dithiocarbamate derivatives, J. Chem. 2014 (2014) 1-9.

33 J. Xu, J. He, D. Fan, X. Wang, Y. Yang, Aminolysis of polymers with thiocarbonylthio termini prepared by RAFT polymerization: The difference between polystyrene and polymethacrylates, Macromolecules 39 (2006) 8616-8624.

34 J.-J. Yuan, R. Ma, Q. Gao, Y. Wang, S. Cheng, L. Feng, Z. Fan, L. Jiang, Synthesis and characterization of polystyrene/poly(4-vinylpyridine) triblock copolymers by reversible addition-fragmentation chain transfer polymerization and their self-assembled aggregates in water, J. Appl. Polym. Sci. 89 (2003) 1017-1025.

35 L. Yao, M.Z. Rong, M.Q. Zhang, Y.C. Yuan, Self-healing of thermoplastics via reversible addition-fragmentation chain transfer polymerization, J. Mater. Chem. 21 (2011) 9060-9065. 
36 Y. Mao, B.M. Fung, A study of the adsorption of acrylic acid and maleic acid from aqueous solutions onto alumina, J. Colloid Interface Sci. 191 (1997) 216-221.

37 S. Gupta, P.C. Ramamurthy, G. Madras, Covalent grafting of polydimethylsiloxane over surface-modified alumina nanoparticles, Ind. Eng. Chem. Res. 50 (2011) 6585-6593. 38 A.M. El-Kamash, Evaluation of zeolite A for the sorptive removal of $\mathrm{Cs}^{+}$and $\mathrm{Sr}^{2+}$ ions from aqueous solutions using batch and fixed bed column operations, J. Hazard. Mater. 151 (2008) 432-445.

39 National Oceanic and Atmospheric Administration, Acrylic acid, Stabilized, CAMEO Chemicals. (1999). https://cameochemicals.noaa.gov/chemical/28.

40 T. Tomida, K. Hamaguchi, S. Tunashima, M. Katoh, S. Masuda, Binding properties of a water-soluble chelating polymer with divalent metal ions measured by ultrafiltration. poly(acrylic acid), Ind. Eng. Chem. Res. 40 (2001) 3557-3562.

41 T.L. Hill, Statistical mechanics of multimolecular adsorption. IV. The statistical analog of the BET constant $a_{1} b_{2} / b_{1} a_{2}$. Hindered rotation of a symmetrical diatomic molecule near a surface, J. Chem. Phys. 16 (1948) 181-189.

42 B.N. Dickhaus, R. Priefer, Determination of polyelectrolyte $\mathrm{pK}$ a values using surface-to-air tension measurements, Colloids Surfaces A 488 (2016) 15-19.

Scheme 1. Schematic illustration of synthesis of asymmetric trithiocarbonate RAFT chain transfer agent (CTA) and in situ preparation of poly(acrylic acid) from acrylic acid in the presence of alumina.

Figure 1. FT-IR spectrum of trithiocarbonate RAFT chain transfer agent (CTA).

Figure 2. ${ }^{1} \mathrm{H}$ NMR spectrum of trithiocarbonate RAFT chain transfer agent (CTA).

Figure 3. Mass spectrum of trithiocarbonate RAFT chain transfer agent (CTA).

Figure 4. FT-IR spectra of alumina adsorbed with acrylic acid (a) and in situ polymerized PAA (b).

Figure 5. TG traits of alumina adsorbed with acrylic acid (a), (c) and in situ polymerized PAA (b) and (d).

Scheme 2. Schematic presentation of PAA distribution in the formed PAA/alumina composite after the RAFT polymerization of acrylic acid monomers adsorbed in alumina pores. Red dots represent acrylic acid molecules and red lines represent PAA chains.

Figure 6. Henderson-Hasselbach plot of PAA in composite samples titrated with $\mathrm{NaOH}$.

Figure 7. Kinetics (a) and pH effects (b) of lead sorption on PAA/alumina composites.

Figure 8. Equilibrium lead sorption amounts and PAA adsorption amounts of wet impregnation (a) and incipient wetness impregnation (b) composite samples.

Table 1. Adsorption amount $\left(\mu \mathrm{g} \mathrm{m}^{-2}\right)$ and efficiency of acrylic acid in $\mathrm{AA} / \gamma-\mathrm{Al}_{2} \mathrm{O}_{3}$ samples 
Table 2. Adsorption amount $\left(\mu \mathrm{g} \mathrm{m}^{-2}\right)$ and retention efficiency of PAA in $\mathrm{PAA} / \gamma-\mathrm{Al}_{2} \mathrm{O}_{3}$ samples

Table 3. Physicochemical characteristics of pristine alumina and select composites, and calculated values assumed uniform coverage of PAA on alumina surface in composites

Table 4. PAA solution dissociation constants of select composites

Table 5. Comparison of add-up Pb concentration (mg L-1) by combined supernatant and digested measurements after composite adsorption versus initially concentration 


\begin{tabular}{|c|c|c|c|c|}
\hline & \multirow{2}{*}{$\begin{array}{l}\text { adsorption } \\
\text { amount }\end{array}$} & \multirow{2}{*}{$\begin{array}{l}\text { adsorption } \\
\text { efficiency }\end{array}$} & \multicolumn{2}{|c|}{ AA layers } \\
\hline & & & $a$ & $b$ \\
\hline $\mathrm{M}_{10, \mathrm{w}} / \mathrm{Al}$ & 93.18 & - & 0.24 & 0.27 \\
\hline $\mathrm{M}_{50, \mathrm{w}} / \mathrm{Al}$ & 272.55 & - & 0.71 & 0.80 \\
\hline $\mathrm{M}_{90, \mathrm{w}} / \mathrm{Al}$ & 279.47 & - & 0.72 & 0.82 \\
\hline $\mathrm{M}_{10, \mathrm{in}} / \mathrm{Al}$ & 173.58 & $79.89 \%$ & 0.45 & 0.51 \\
\hline $\mathrm{M}_{50, \mathrm{in}} / \mathrm{Al}$ & 631.09 & $58.09 \%$ & 1.63 & 1.85 \\
\hline $\mathrm{M}_{90, \mathrm{in}} / \mathrm{Al}$ & 1071.31 & $54.78 \%$ & 2.78 & 3.13 \\
\hline
\end{tabular}

$a$ Calculated according to Eq. (1).

$b$ Estimated using data from ref 36.

T 2

\begin{tabular}{lcccc} 
& adsorption & retention & \multicolumn{2}{c}{ PAA layers } \\
& amount & efficiency & $a$ & $b$ \\
\hline $\mathrm{P}_{10, \mathrm{w}} / \mathrm{Al}$ & 54.96 & $58.98 \%$ & 0.14 & 0.16 \\
$\mathrm{P}_{50, \mathrm{w}} / \mathrm{Al}$ & 69.02 & $25.32 \%$ & 0.18 & 0.20 \\
$\mathrm{P}_{90, \mathrm{w}} / \mathrm{Al}$ & 137.31 & $49.13 \%$ & 0.36 & 0.40 \\
$\mathrm{P}_{10, \mathrm{in}} / \mathrm{Al}$ & 99.11 & $57.10 \%$ & 0.26 & 0.29 \\
$\mathrm{P}_{50, \mathrm{in}} / \mathrm{Al}$ & 511.89 & $81.11 \%$ & 1.33 & 1.50 \\
$\mathrm{P}_{90, \mathrm{in}} / \mathrm{Al}$ & 794.80 & $74.18 \%$ & 2.06 & 2.32 \\
\hline
\end{tabular}

$a$ Calculated according to Eq. (1). 
$b$ Estimated using data from ref 36.

T 3

\begin{tabular}{cccc}
\hline & BET area $\left(\mathrm{m}^{2} \mathrm{~g}^{-1}\right)$ & pore volume $\left(\mathrm{mLg}^{-1}\right)$ & pore diameter(nm) \\
$\gamma-\mathrm{Al}_{2} \mathrm{O}_{3}$ & 174.5 & 0.3611 & 8.278 \\
$\mathrm{P}_{10 \text { in }} / \mathrm{Al}$ & 155.4 & 0.3061 & 7.878 \\
$\mathrm{cal}$. & 171.1 & 0.3471 & 8.117 \\
$\mathrm{P}_{90, \text { in }} / \mathrm{Al}$ & 153.3 & 0.2496 & 6.513 \\
cal. & 147.2 & 0.2572 & 6.986 \\
\hline
\end{tabular}

T 4

\begin{tabular}{ccccc}
\hline & $\beta$ & $K_{\mathrm{a}}$ & $\mathrm{p} K_{\mathrm{a}}$ & $R^{2}$ \\
\hline $\mathrm{P}_{10, \mathrm{in}} / \mathrm{Al}$ & 1.697 & $6.42 \times 10^{-7}$ & 6.192 & 0.999 \\
$\mathrm{P}_{90, \mathrm{in}} / \mathrm{Al}$ & 1.265 & $2.33 \times 10^{-6}$ & 5.632 & 0.999 \\
\hline
\end{tabular}

T 5

\begin{tabular}{lccccc}
\hline & initial & supernatant & digested & add-up & RSD \\
\hline $\mathrm{P}_{10, \text { in }} / \mathrm{Al}$ & 60.000 & 26.477 & 35.374 & 61.851 & $3.09 \%$ \\
$\mathrm{P}_{90, \mathrm{in} / \mathrm{Al}}$ & 60.000 & 23.754 & 36.936 & 60.690 & $1.15 \%$ \\
\hline
\end{tabular}


Figure(s)

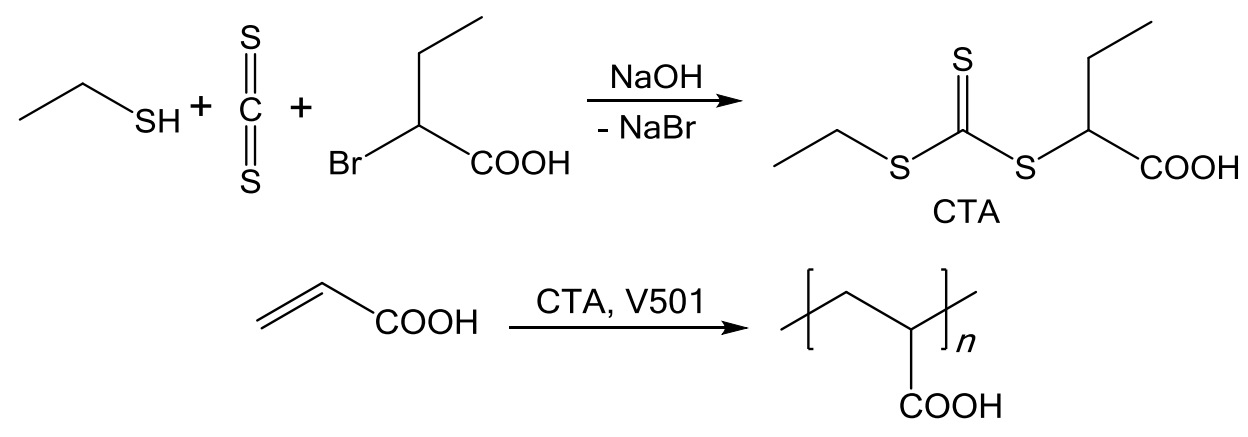

S 1 


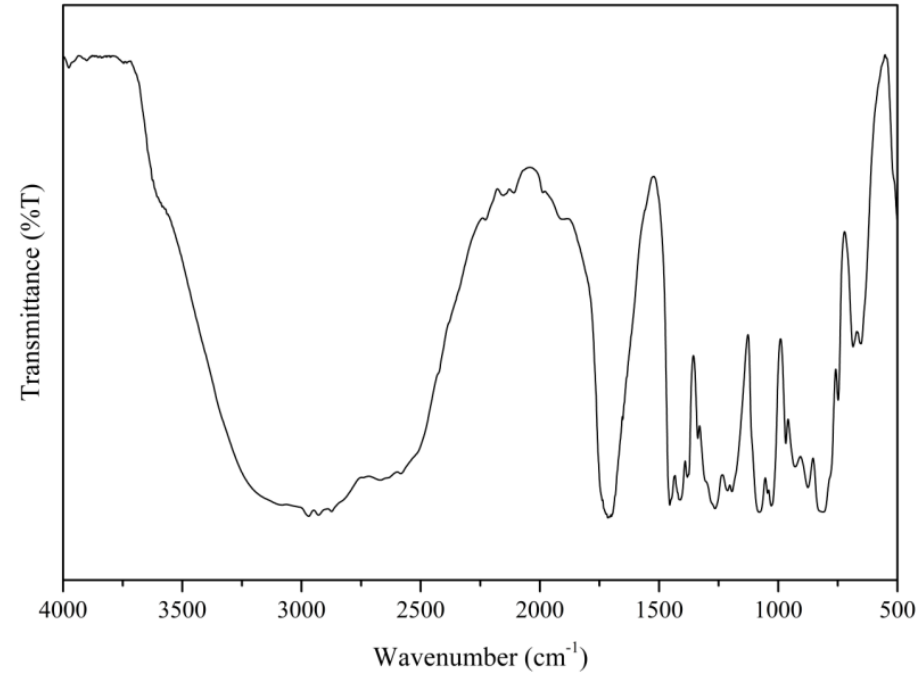

F 1 


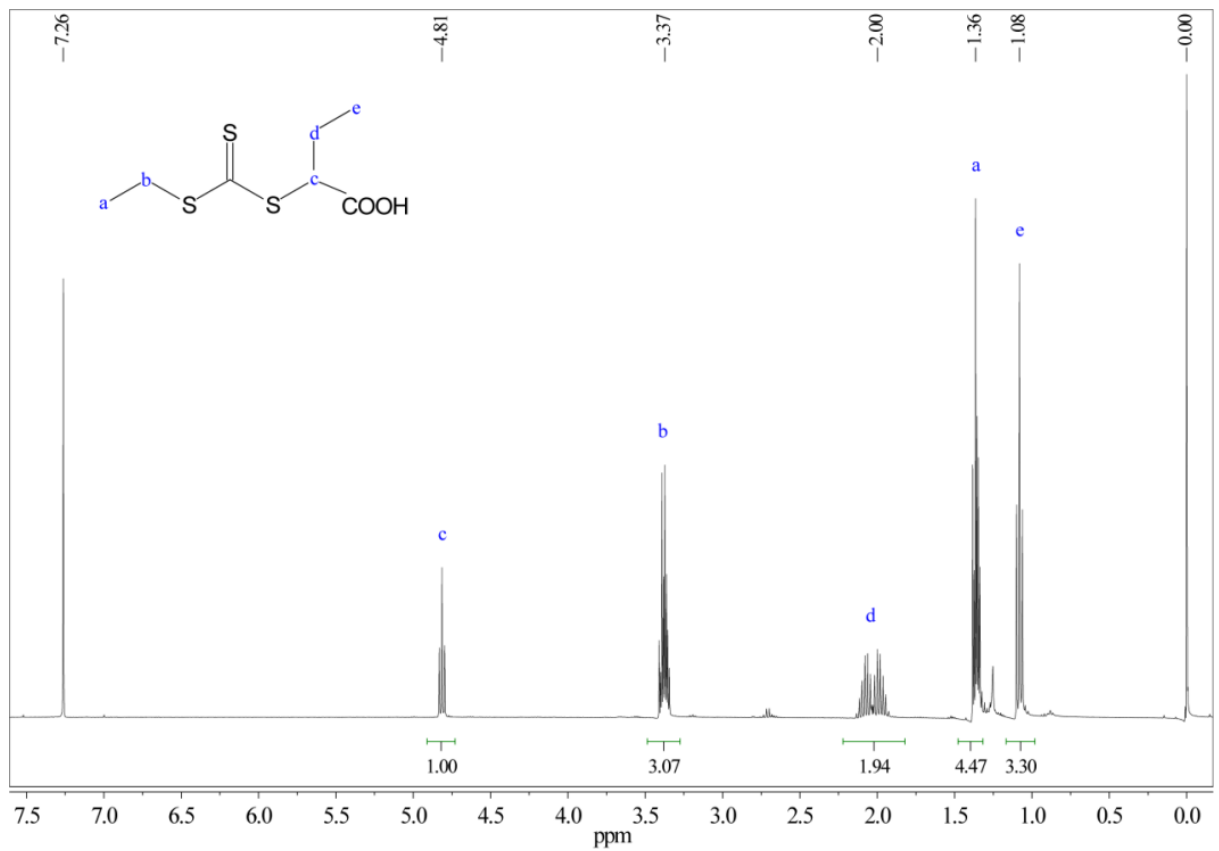

F 2 


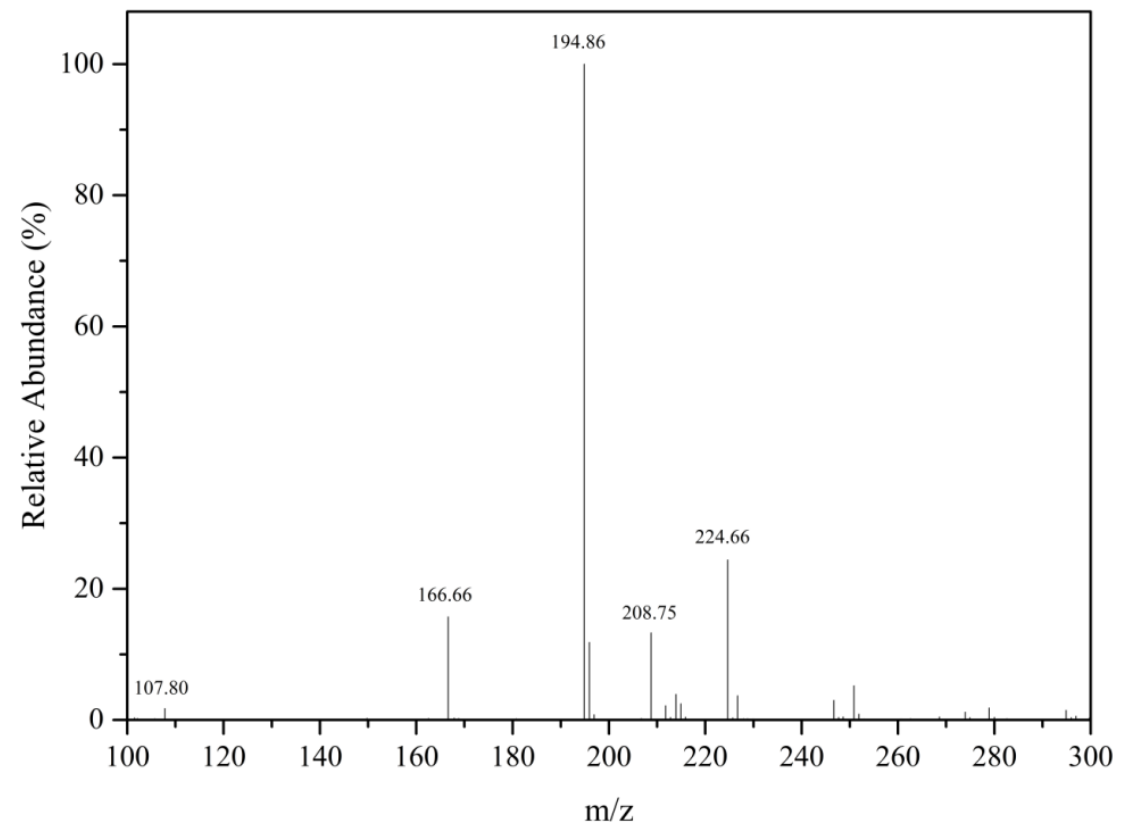

F 3 


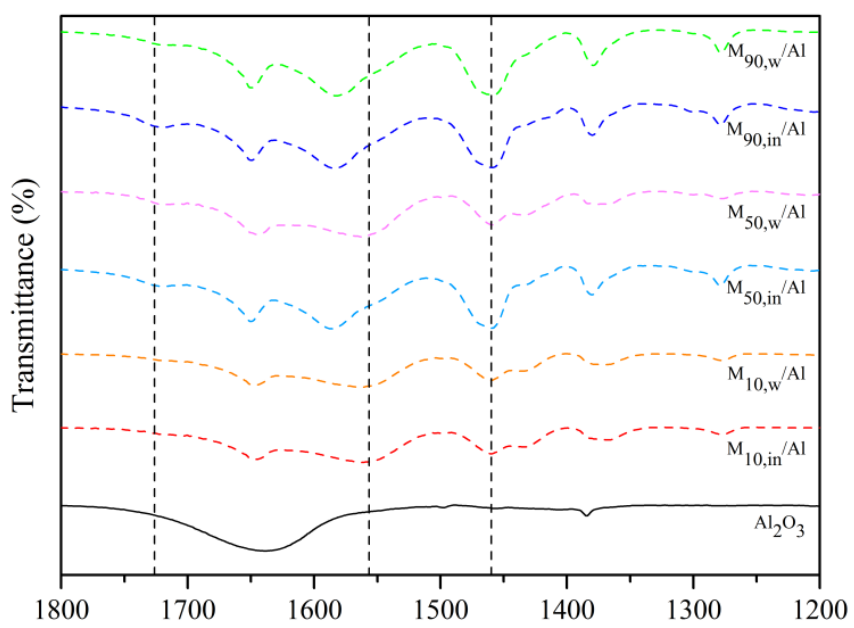

(a)

Wavenumber $\left(\mathrm{cm}^{-1}\right)$

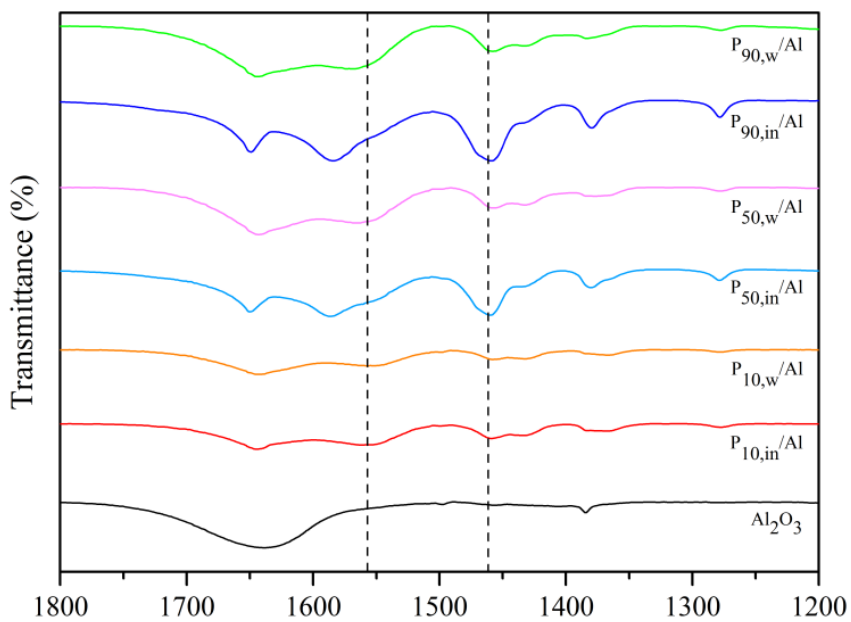

(b) Wavenumber $\left(\mathrm{cm}^{-1}\right)$

F 4 


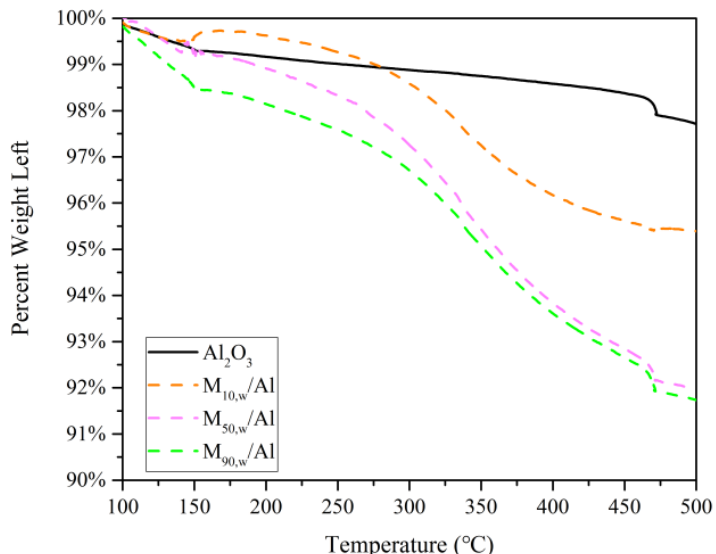

(a)

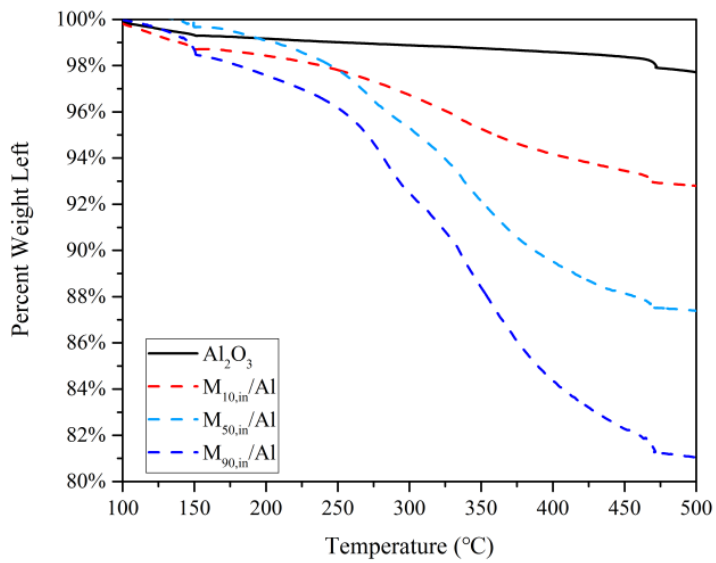

(c)

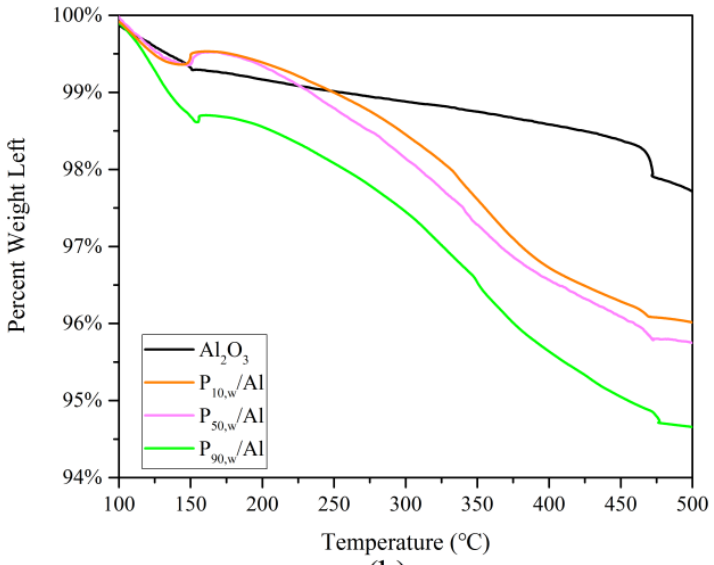

(b)

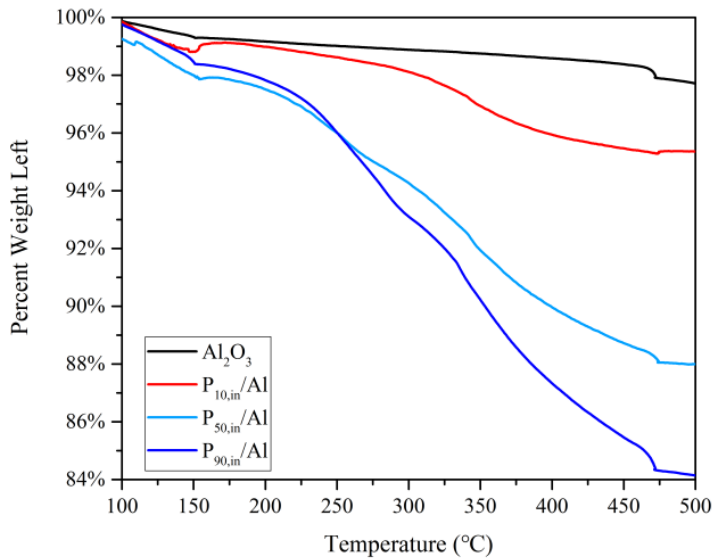

(d)

F 5 


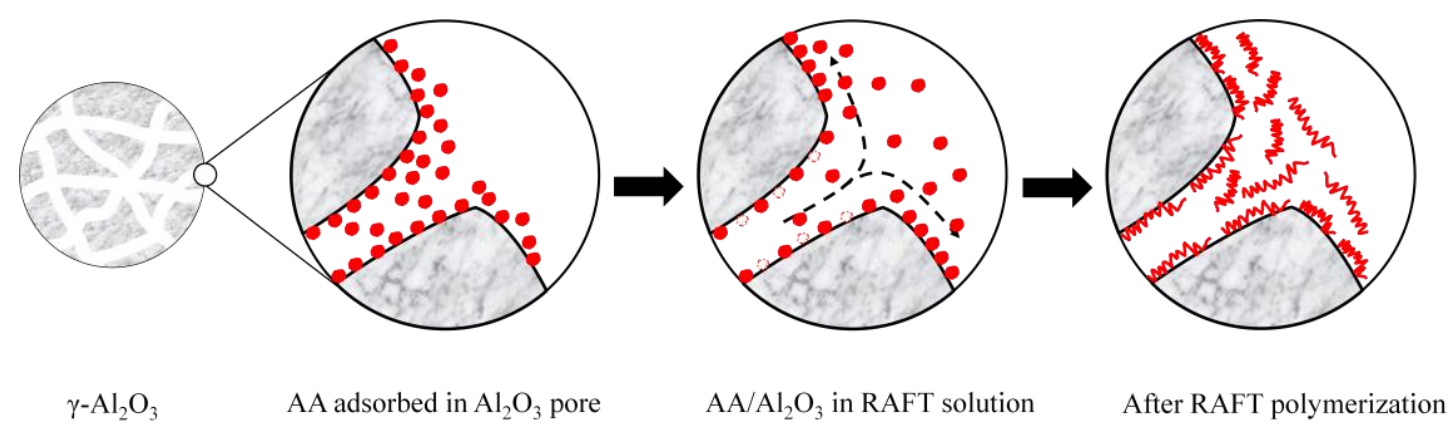

S 2 


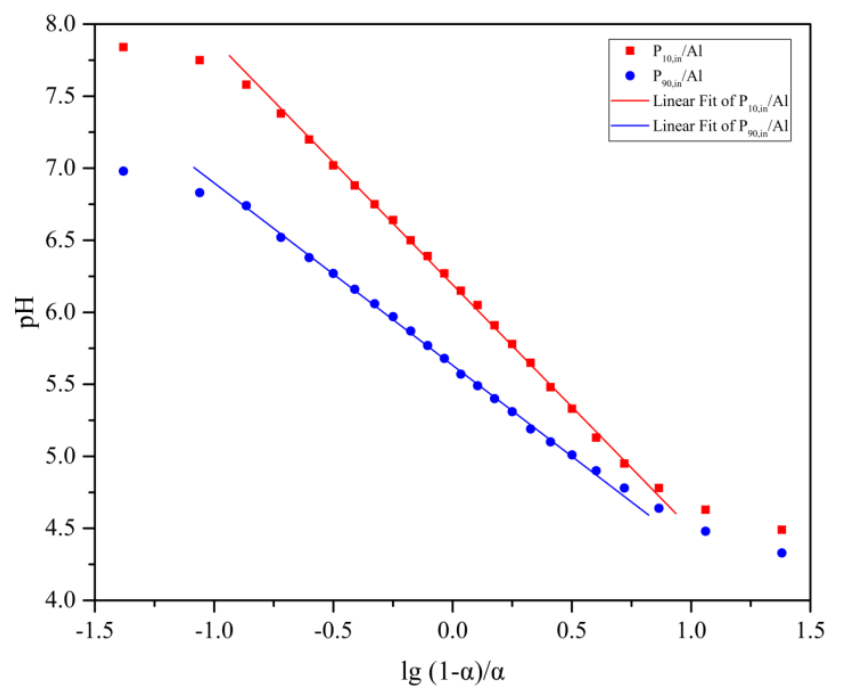

F 6 


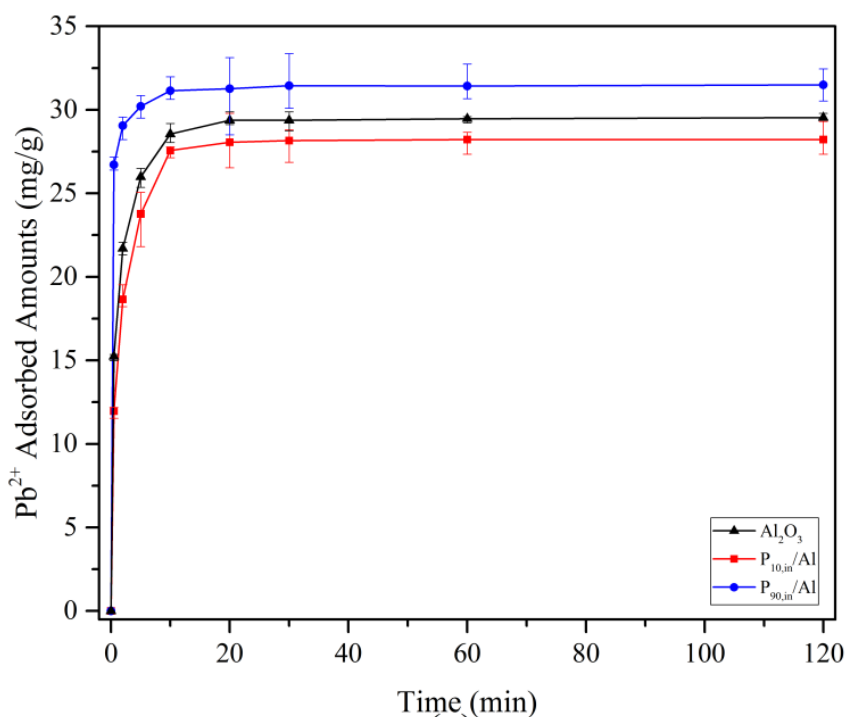

(a)

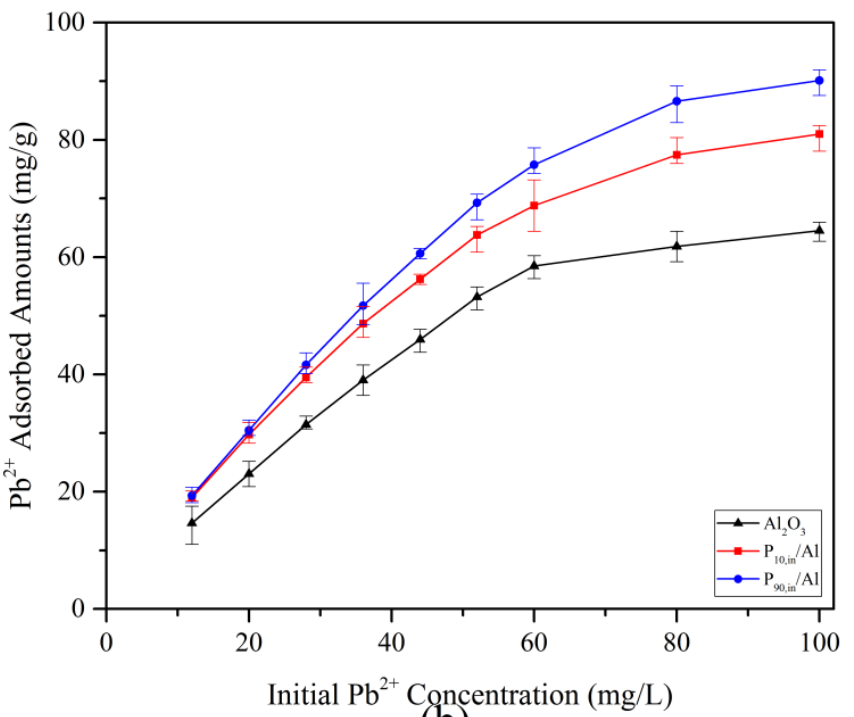

(b)

F 7 


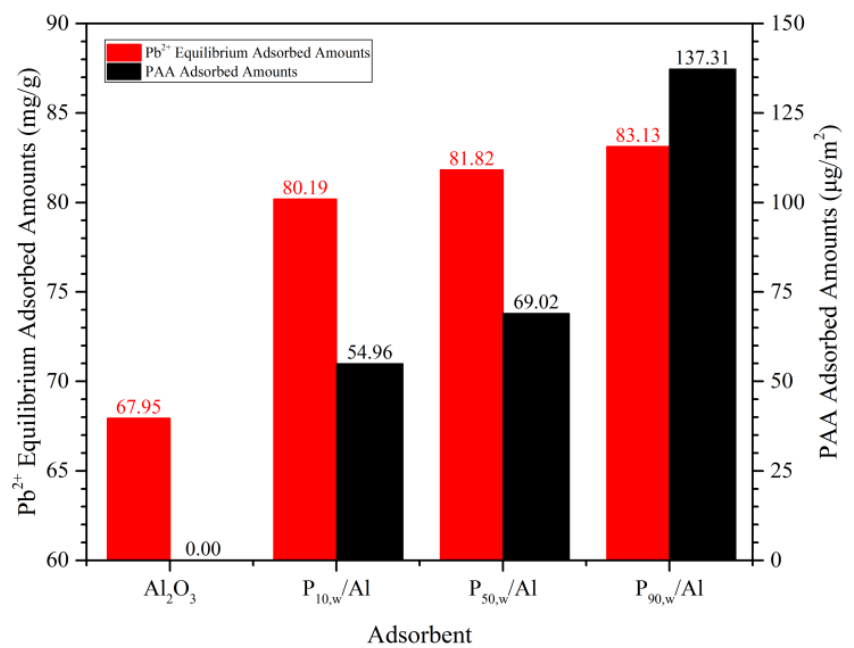

(a)

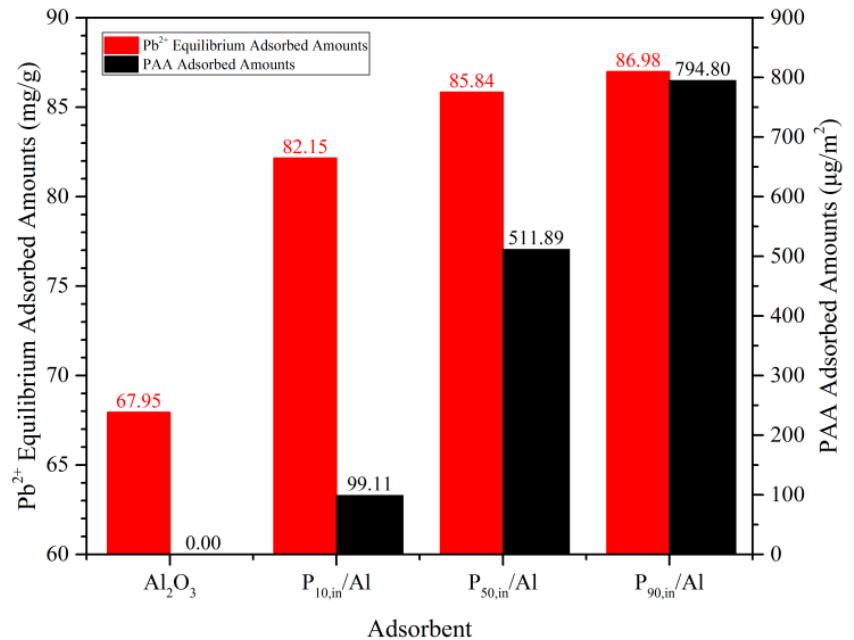

(b)

F 8 


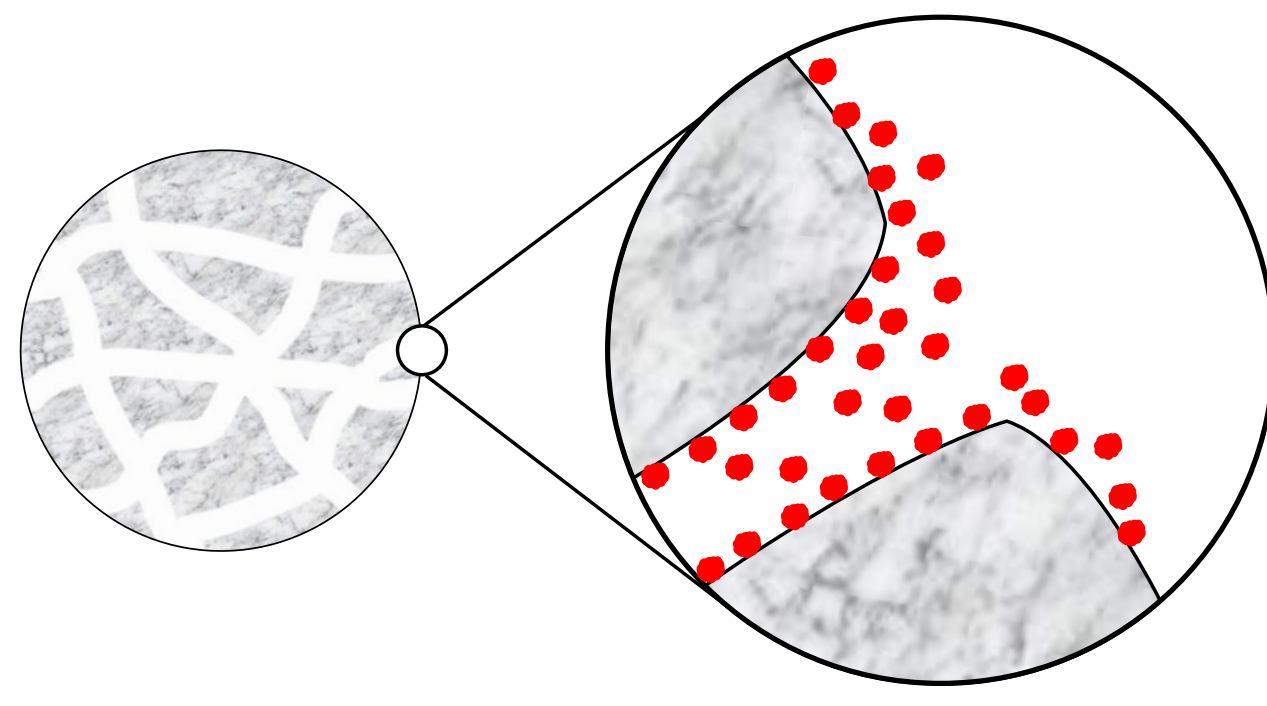

$\gamma-\mathrm{Al}_{2} \mathrm{O}_{3}$
AA adsorbed in $\mathrm{Al}_{2} \mathrm{O}_{3}$ pore

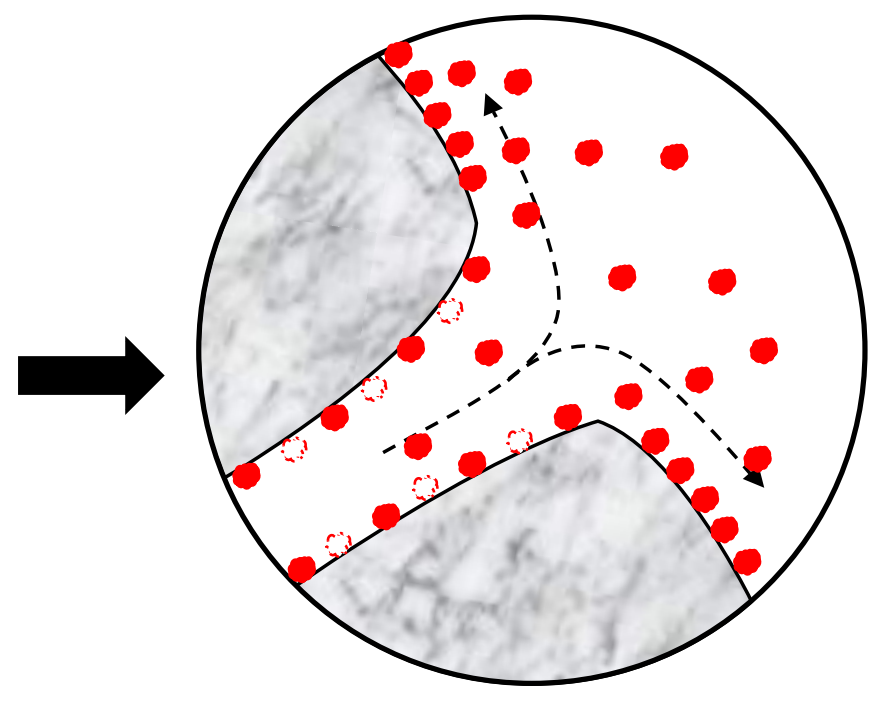

$\mathrm{AA} / \mathrm{Al}_{2} \mathrm{O}_{3}$ in RAFT solution

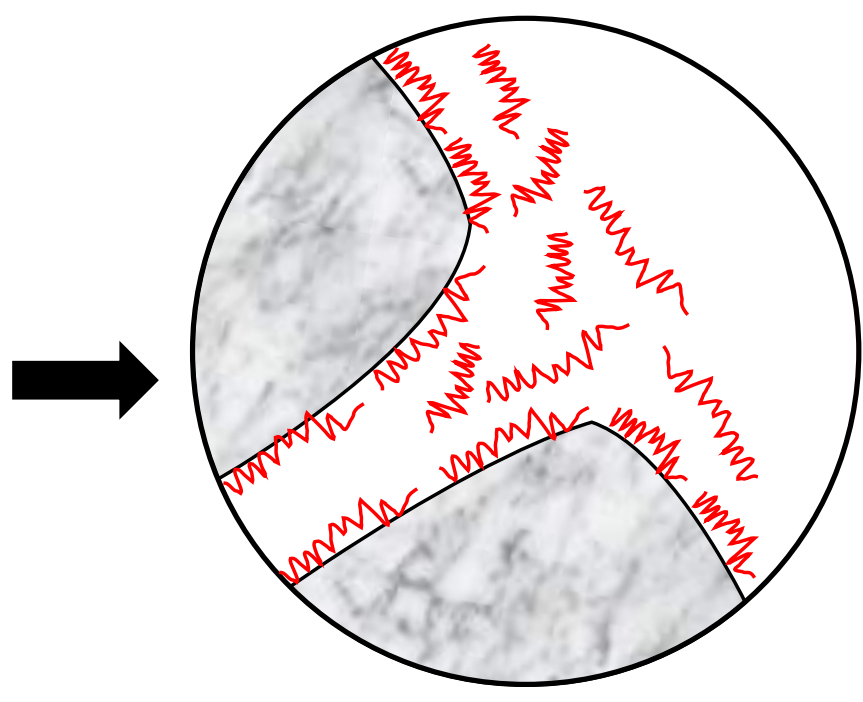

After RAFT polymerization 